\title{
Capital Adequacy Ratio, Bank Size and Commercial Bank Risk Bearing: Empirical Analysis Based on 16 Listed Commercial Banks
}

\author{
Qiang Li, Chunmian Qin \\ School of Finance, Guizhou Financial and Economical University, Guiyang 550025 ,China

\section{资本充足率、银行规模与商业银行风险承担 :基于 16 家上市商业银行的实证分析}

李强, 覃春面

贵州财经大学金融学院, 贵阳 550025, 中国

\begin{abstract}
Based on the panel data of 16 listed commercial banks in China from 2005 to 2017, this paper uses LS panel data model to analyze the relationship between capital adequacy ratio, bank size and risk bearing of commercial banks in China. The empirical results show that increasing the capital adequacy ratio can reduce the risk bearing behavior of commercial banks; The scale of the bank has a significant negative correlation with the risk bearing behavior of commercial banks in China. The larger the scale, the lower the risk bearing behavior of the bank; Under the condition of increasing the bank size, the capital adequacy ratio has a significant positive correlation with the risk assumption of the commercial bank, that is, the size of the bank inhibits the restraint of the capital adequacy ratio on the risk assumption behavior of the commercial bank to a certain extent. Finally, it is concluded that China's regulatory authorities should fully consider the role of different bank sizes in risk taking when preventing bank risks, and adopt a differentiated capital adequacy ratio system.
\end{abstract}

Key words: Capital adequacy ratio; Bank size; Commercial bank risk

摘要

本文基于 2005 年-2017 年我国 16 家上 市商业银行的面板数据, 采用 LS 的面板数 据模型实证分析了我国资本充足率、银行规 模以及商业银行风险承担之间的关系。实证 结果表明: 提高资本充足率可以降低商业银 行的风险承担行为; 银行规模对我国商业银 行的风险承担行为也具有显著的负相关关 系, 规模越大, 银行的风险承担行为越低; 在增加银行规模的条件下资本充足率与商 业银行风险承担具有显著的正相关关系, 即 银行规模在一定程度上抑制资本充足率对 商业银行风险承担行为的约束作用。最后得 出我国监管当局在防范银行风险时应充分 考虑不同银行规模在风险承担中的作用，采 取差别化的资本充足率制度。

关键词：资本充足率; 银行规模; 商业银行 风险

1. 引言

自 2008 年席卷全球的金融危机爆发以 来, 世界各国开始反思银行等金融机构在此 次危机爆发中所扮演的角色。世界各国普遍 认为加大银行资本充足率的监管是能够约 束商业银行风险的重大因素之一。Abdullah 
Alam(2012) ${ }^{[1]}$ 基于 VAR 和 OLS 方法探索全 球金融危机的传播途径, 并得出叫醒电话和 现金效应是金融危机传播的主要途径。因此, 为了避免金融危机的再次发生, 国际金融监 管机构颁发新的监管标准, 即巴塞尔协议 III 出台, 该标准进一步规范并提高了资本充足 率至 $8 \%$, 并要求核心资本必须达到 $4 \%$ 以上。 我国银监会为了尽快与新的国际监管标准 接轨, 并于 2012 年 6 月出台了《商业银行资 本充足率管理办法 (试行) 》, 该办法规范 了处于我国重要地位的商业银行资本充足 率要达到 $11.5 \%$ 以上, 其他银行机构要求达 到 $10.5 \%$ 以上。尽管各个银行机构都尽力达 到该标准, 并且部分银行也达到了此要求, 但由于我国经济发展不平衡, 金融业发展也 较晚, 银行经营理念、发展规划、追求利益 目标等不一致, 投资者理财观念、风险偏好 也不同, 以及受到长期封建思想的束缚而导 致的心理承担能力也较差等原因也导致仍 有部分银行的资本存在重大缺口。

所以对于运用资本充足率来加大商业 银行风险的监管是否有效还亟需进一步考 证, 同时对于不同规模的银行, 加大资本充 足率来控制风险承担行为是否有异质性也 需要进一步分析, 尽管不少研究得出提高资 本充足率可以降低银行风险, 以及银行规模 与商业银行风险存在U型关系的结论, 但鲜 少有把资本充足率与银行规模两者结合一 起来分析资本充足率、银行规模以及商业银 行风险承担的影响关系, 因此研究我国的资 本充足率、银行规模与商业银行风险承担行 为具有一定的现实意义。

\section{2. 文献综述}

关于银行规模与商业银行风险承担的 相关文献研究较为丰富。徐明东、陈学彬 (2012) [2]采用 GMM 动态面板估计方法验 证发现银行规模越大、资本充足率越高, 银 行风险承担行为对货币政策敏感性越低。吴 亚、刘瑞环 (2014) ${ }^{[3]}$ 基于 2005-2012 年的 18 家商业银行的数据实证研究发现, 我国商 业银行的风险承担行为与商业银行规模存 在 $U$ 型结构, 而国有商业银行的规模值在 $U$ 型的右侧, 非国有商业银行的规模在 U 型结 构的左侧。刘志洋 (2015) ${ }^{[4]}$ 通过对中国上
市商业银行的面板数据实证研究发现商业 银行的规模与商业银行的风险包括经营风 险、系统风险以及非系统风险负相关。谢俊 明（2015） ${ }^{[5]}$ 基于 16 家上市商业银行的数据 实证发现, 商业银行规模与商业银行的风险 承担行为呈正向关系, 大型商业银行、股份 制商业银行以及城市商业银行的风险承担 行为依次降低。唐齐鸣、马丽 (2017) ${ }^{[6]}$ 通 过实证发现, 银行规模越大, 银行风险承担 越低, 但是在利率市场化条件下会降低银行 规模在风险承担中的作用。周再清等 (2017) [7]进一步分析商业银行规模中的同业资产规 模及结构特征对风险承担行为的影响状况, 发现同业资产业务扩张提高银行的风险承 担行为, 而在结构特征中, 传统的同业资产 业务扩张对银行风险呈负向效应, 新兴同业 资产业务扩张对银行风险承担呈正向效应。 喻微锋、周黛 (2018) ${ }^{[8]}$ 采用动态广义矩与 面板门槛模型的实证发现, 不同的银行规模 下, 互联网金融对商业银行风险的影响具有 异质性。

随着金融危机的爆发以及 《巴塞尔协议》 频繁改动, 资本监管即资本充足率的研究成 为学术界的热点。蔡允革 (2008) ${ }^{[9]}$ 基于 14 家商业银行的实证研究结果发现, 商业银行 资本充足率水平的提升得益于政府的注资, 而加大资本监管对解决银行资本不足的问 题效果不明显, 同时资本监管的压力也不能 缓解近几年的商业银行资产风险水平。江曙 霞、任婕茹（2009） ${ }^{[10]}$ 基于 1998-2007 年美 国商业银行数据进行分析发现资本充足率 监管对不同银行实行的“差别待遇”会拉大银 行风险敞口, 未能达到理想的监管目标。陈 冠华、杨晓奇 (2010) ${ }^{[11]}$ 发现资本变动与风 险变动呈负相关, 并通过计算发现我国商业 银行资本监管的有效程度介于 $0.25 \%-5 \%$ 之 间, 从而得出为提高资本监管的有效性而应 增加资本监管的激励相容性的建议。魏晓琴 等 (2011) ${ }^{[12]}$ 实证发现我国商业银行的资本 充足率通过资本结构的变化与商业银行的 风险资产呈现相互影响的状态。潘佐郑 (2013) ${ }^{[13]}$ 得出加大对商业银行的资本充足 监管有助于降低商业银行的风险, 提高银行 的风险管理能力。尹志超等 (2014) ${ }^{[14]}$ 在研 
究中发现市场化程度的提高在增大商业银 行风险的条件下, 进一步发现市场化的推进 也使商业银行资本充足率下降, 追其原因主 要是市场化进程中银行风险资产增加的结 果。牛丽娟 (2015) ${ }^{[15]}$ 通过面板数据的实证 研究发现资本充足率与商业银行风险承担 显著负相关，而加入股东性质发现，资本充 足率与股东性质的交叉项发现与风险承担 显著正相关。

大量的文献研究局限在银行规模或者 资本充足率单一的要素对银行风险的影响 进行细致的研究, 而未能将资本充足率、银 行规模以及商业银行风险承担三者纳入统

\section{3. 研究设计}

\section{1 模型设定}

为研究资本充足率、银行规模与商业银 行风险承担的影响以及银行规模是否影响
一的框架进行分析探讨。同时针对资本充足 率运用面板数据进行的实证研究也相当贵 乏, 从多角度衡量的银行风险实证研究也尚 不多见。此外, 针对资本充足率的相关研究 在近几年也未能得到充分的探讨, 选用的数 据也较为滞后, 难以全面反映最新的发展态 势。通过本文的研究, 可以进一步分析银行 规模在资本充足率对商业银行风险承担机 制中的作用, 可以有效约束不同银行规模下 资本充足率对商业银行风险承担的影响, 有 利于银行监管机构做出符合实际的政策措 施。

资本充足率和商业银行风险承担之间的关 系, 本文设定以下三个模型:

$$
\begin{aligned}
& N P L=a_{0}+a_{1} R C A_{i t}+a_{2} R O E_{i t}+G D P_{t}+\varepsilon_{i t} \\
& N P L=\partial_{0}+\partial_{1} S I N E_{i t}+\partial_{2} R O E_{i t}+\partial_{3} G D P_{t}+\varepsilon_{i t} \\
& N P L=\omega_{0}+\omega_{1} R C A_{i t}+\omega_{2} S I N E_{i t}+\omega_{3} S I N E_{i t} \times R C A_{i t}+\omega_{4} R O E_{i t}+\omega_{5} G D P_{t}+\varepsilon_{i t}
\end{aligned}
$$

其中 $i$ 代表商业银行, $t$ 代表年份, $\varepsilon_{i t}$ 代表随机扰动项。

\section{2 数据来源和变量选择}

本文的研究样本为 2005-2017 年间我国 16 家上市商业银行的面板数据, 大部分的数 据均来源于各家商业银行的年度报表, 其中 GDP 增长率来自世界银行。以 2005 年的数 据为起点主要是因为 2005 年我国大部分商 业银行开始进行股份制改革, 商业银行通过 不断剥离不良资产、完善内部制度, 增加注 册资本, 引入战略性投资者, 公开上市等方 式来完善公司治理机制, 使得 2005 年的数据 更具有合理性和说服性, 同时有个别银行早 年的数据有部分缺失, 所以本文采用序列平 均值法来替换缺失值。

（1）被解释变量。借鉴 Shrieves 和 Dahl (1992) ${ }^{[16]}$ 的做法, 本文选取不良贷款率来 衡量商业银行的风险承担。不良贷款率 (NPL) 作为衡量商业银行风险的指标, 信用风险是 商业银行面临的主要风险, 不良贷款正是信 用风险的反映, 所以运用不良贷款率作为被
解释变量来研究具有一定的合理性。

(2) 解释变量。资本充足率 (RCA) 作为银行监管的重要指标, 是本文的解释变 量之一。指的是一个银行的资本总额对其风 险加权资产的比率。资本充足率的变动会影 响到商业银行的经营策略和风险偏好, 本文 依据徐明东等 (2012) 的实证结果预期资本 充足率与银行风险呈负相关。银行规模是本 文的另一解释变量, 本文采用资产总额来反 映, 即 SINE, 一般来说规模大的银行预期 能够管理控制并有效分散风险, 然而大银行 更能够获取信息优势的金融安全网而拥有 “大而不倒”的态势, 从而能更加增加其风险 承担行为。此外, 为了得到不同规模下加大 资本充足率的监管对银行风险的影响程度 状况, 本文采用资本充足率和银行规模的交 叉项来反映, 即 SINE $\times$ RCA。

（3）其他控制变量。GDP 增长率: 宏 观经济环境对商业银行的风险承担具有同 周期的作用, GDP 增长率恰好是反映一国的 
宏观经济环境水平, 本文采用 GDP 符号来衡 量, 即 GDP。净资产收益率（ROE）：由于 各家银行数据统计的不一致性, 本文把净资

4. 实证检验
产收益率、净资产回报率、全面摊薄的净资 产收益率以及加权平均净资产收益率视为 一个近视变量来做一个统计分析数据。

\section{1 数据的描述性统计}

表 1 相关变量的描述性统计资料

\begin{tabular}{cccccccccc}
\hline 变量 & 均值 & 中位数 & 最大值 & 最小值 & 标准差 & 偏度 & 峰度 & JB & N \\
\hline NPL (\%) & 2.00899 & 1.385 & 26.17 & 0.33 & 3.063488 & 5.960943 & 42.77901 & 14945.68 & 208 \\
RCA (\%) & 11.80817 & 11.75 & 30.67 & -1.47 & 2.935832 & 0.729548 & 14.83898 & 1233.184 & 208 \\
SINE (百万元) & 4862219 & 2411942 & 26087043 & 42429 & 5751534 & 1.673636 & 5.049968 & 133.5239 & 208 \\
ROE (\%) & 18.14591 & 18.15 & 36.71 & -6.63 & 4.633337 & -0.349951 & 7.489684 & 178.9418 & 208 \\
GDP (\%) & 9.269231 & 9.2 & 14.2 & 6.7 & 2.298795 & 0.716594 & 2.46214 & 20.30878 & 13 \\
\hline
\end{tabular}

表 1 给出了各变量的描述性统计结果。 从中可以看出 16 家上市商业银行的不良贷 款率平均值为 $2.00899 \%$, 最小值为 2006 年 宁波银行的 $0.33 \%$, 最大值为 2005 年中国农 业银行的 $26.17 \%$, 其最大值 $26.17 \%$ 是其不 良贷款率平均值的约 12 倍, 差异巨大, 其 主要原因是 2005 年中国农业银行尚未进行 股份制改革以及未得到政府注资, 这种状况 非常罕见, 不具有普遍意义。资产总额平均 值为 4862219 百万元人民币, 最小值为 2005 年宁波银行的 42429 百万元人民币, 最大值 为中国工商银行的 26087043 百万元人民币， 中国工商银行的资产总额即银行规模是目 前最大的金融机构, 是最小值宁波银行 42429 百万元的 600 多倍, 是目前商业银行 的龙头企业。资本充足率水平也普遍较高,
其平均值达到 $11.80817 \%$, 从目前的形式来 看, 绝大多数商业银行的资本充足率已达到 国际银行监管标准巴赛尔协议资本充足率 $8 \%$ 的要求, 但也有出现最小值负数的资本充足 率状况, 是 2005 年中国光大银行的-1.47\%, 其主要原因是中国光大银行在 2005 年的核 心资本净额为负值。而控制变量净资产收益 率和 GDP 增长率的平均值分别为 $18.14591 \%$ 和 9.27\%, 净资产收益率也出现负值状况, 达到-6.63\%, 主要原因是 2006 年广东发展银 行出现负值的净利润, 是亏损状态, GDP 增 长率最大值为 2007 年的 $14.2 \%$, 而近几年我 国经济发展步入新常态, GDP 增长率从 2010 年开始有所下降, 但近两年开始有所回升, 2017 年 GDP 增长率已达到 6.9\%。

表 2 模型选择的检验结果分析表

\begin{tabular}{|c|c|c|c|c|c|}
\hline \multicolumn{2}{|c|}{ 模型（1） } & \multicolumn{2}{|c|}{ 模型（2） } & \multicolumn{2}{|c|}{ 模型（3） } \\
\hline \multicolumn{6}{|c|}{$\mathbf{F}$ 检验 } \\
\hline $\mathrm{S}$ 统计量 & $\mathrm{P}$ 值 & $\mathrm{S}$ 统计量 & $\mathrm{P}$ 值 & $\mathrm{S}$ 统计量 & $\mathrm{P}$ 值 \\
\hline 4.633333 & 0.0000 & 5.353684 & 0.0000 & 7.10272 & 0.0000 \\
\hline \multirow{2}{*}{\multicolumn{2}{|c|}{ 拒绝原假设 }} & \multicolumn{2}{|c|}{ 拒绝原假设 } & \multicolumn{2}{|c|}{ 拒绝原假设 } \\
\hline & & \multicolumn{2}{|c|}{ hausman 检验 } & & \\
\hline $\mathrm{S}$ 统计量 & $\mathrm{P}$ 值 & $\mathrm{S}$ 统计量 & $\mathrm{P}$ 值 & $\mathrm{S}$ 统计量 & $\mathrm{P}$ 值 \\
\hline 0 & 1.0000 & 0 & 1.0000 & 58.220051 & 0.0000 \\
\hline \multicolumn{2}{|c|}{ 接受原假设 } & \multicolumn{2}{|c|}{ 接受原假设 } & \multicolumn{2}{|c|}{ 拒绝原假设 } \\
\hline
\end{tabular}




\section{2 模型的选择与回归分析}

为了方便分析和比较, 本文分别对模型 的混合效应、个体固定效应以及个体随机效 应模型进行检验估计。表 2 给出了 $\mathrm{F}$ 检验和 hausman 检验的结果, 模型 (1) 是资本充 足率与商业银行的风险承担的回归, 模型 (2) 是银行规模与商业银行风险承担的回归, 模 型（3）是资本充足率、银行规模与商业银 行风险承担的回归。首先从 $\mathrm{F}$ 检验确定是选 用混合效应模型还是个体固定效应模型, 从
中可以看出, 三个模型的 $\mathrm{P}$ 值均为 0 , 显著 拒绝原假设为混合效应模型的假设, 所以排 除混合模型。其次从 hausman 检验中确定是 建立随机效应模型还是固定效应模型, 同样 从表 2 可以看出, 模型 (1) 和模型 (2) 的 统计量为 $0, P$ 值为 1 , 接受为随机效应模型 的原假设, 所以模型 (1) 和模型 (2) 选用 随机效应模型, 而模型 (3) 的 $\mathrm{s}$ 统计量 58.22, $\mathrm{P}$ 值为 0 , 显著拒绝原假设, 所以建立个体 固定效应模型。

表 3 银行规模、资本充足率与商业银行风险承担的回归结果

\begin{tabular}{|c|c|c|c|}
\hline & (1) NPL & (2) NPL & (3) NPL \\
\hline \multirow{2}{*}{$\mathrm{RCA}$} & $-0.212675^{* * *}$ & & $-0.241557^{* * * *}$ \\
\hline & $(-2.885991)$ & & $(-3.256312)$ \\
\hline \multirow{2}{*}{ SINE } & & $-6.47 \times 10^{-8}$ & $-2.32 \times 10^{-6 * * *}$ \\
\hline & & $(-1.202213)$ & $(-5.499480)$ \\
\hline SINE $\times$ RCA & & & $\begin{array}{l}1.33 \times 10^{-7^{* * *}} \\
(5.035959)\end{array}$ \\
\hline \multirow{2}{*}{ ROE } & $-0.121659^{* * *}$ & $-0.116866^{* * *}$ & $-0.116907^{* * *}$ \\
\hline & $(-2.886622)$ & $(-2.809109)$ & $(-2.906016)$ \\
\hline \multirow{2}{*}{ GDP } & $0.426401^{* * *}$ & $0.424783^{* * *}$ & 0.010981 \\
\hline & (5.408934) & $(4.726271)$ & (0.104503) \\
\hline $\mathrm{R}^{2}$ & 0.203596 & 0.174979 & 0.489337 \\
\hline Prob $>F$ & 0.000000 & 0.000000 & 0.000000 \\
\hline
\end{tabular}

注: 括号内为 $\mathrm{t}$ 值, $*$ 表示 $10 \%$ 的显著性水平, $* *$ 表示 $5 \%$ 的显著性水平, $* * *$ 表示 $1 \%$ 的显著性水平。

表 3 是资本充足率、银行规模与商业银 行风险承担的回归结果, 从模型（1）的回 归结果可以看出, 资本充足率与商业银行风 险承担显著负相关, 相关系数为 -0.213 , 在 $1 \%$ 水平下显著, 这说明资本充足率的提高可 以降低商业银行的风险承担行为。从模型 (2) 的回归结果来看, 银行规模与商业银行的风 险承担显著负相关, 回归系数 $-6.47 \times 10^{-8}$, 不 显著, 但若光从回归系数上看, 银行规模的 增加会降低商业银行的风险承担。最后在前 述模型的基础上增加银行规模与资本充足 率的交叉项, 目的是为了验证银行规模的增 加对资本充足率与商业银行风险承担关系 的影响状况, 这从模型 (3) 的回归结果可 以看到, 银行规模 $\times$ 资本充足率的回归系数 为 $1.33 \times 10^{-7}$, 与商业银行风险承担显著正相 关, 这说明银行规模越大, 拥有资本充足率 较高的商业银行就更可能通过增加商业银 行风险承担来提高最大化价值。另外, 我们 还发现在增加银行规模的情况下, 资本充足 率的回归系数仍是负值, 并未改变回归系数
的方向, 在三个模型中, 控制变量中净资产 收益率的回归系数均显著为负, 这说明银行 净资产收益率的增加显著降低商业银行的 风险承担, 而 GDP 增长率即经济增长从整体 上有助于增加商业银行的风险承担水平。

\section{5. 结论及建议}

本文基于 2005 年-2017年我国 16 家上市 商业银行的面板数据, 实证分析了我国商业 银行的风险承担与资本充足率、银行规模之 间的关系。实证结果表明: 首先, 商业银行 的资本充足率对银行的风险承担行为具有 一定的约束作用, 提高资本充足率可以降低 商业银行的风险承担行为。其次, 银行规模 对我国商业银行的风险承担行为也具有负 相关关系, 规模越大, 银行的风险承担行为 越低。最后, 引入银行规模与资本充足率的 交叉项发现资本充足率在增加银行规模的 条件下与商业银行风险承担具有显著的正 相关关系, 即银行规模在一定程度上抑制资 本充足率对商业银行风险承担行为的约束 
作用。

所以, 从实证结果得出, 在我国的经济 背景下, 我国银监会应该把银行规模这一因 素考虑到资本充足率的管理办法中来, 直面 银行规模在商业银行风险管理中的角色, 在 不同规模的银行机构背景下采取差别化的 资本充足率要求, 进一步规避银行规模在资 本充足率与商业银行风险承担关系中的影 响, 提高我国商业银行的风险防范能力, 加 强我国金融体系分稳定性。

\section{基金项目}

国家社科基金项目 “基于混合 Copula 的中国 系统性金融风险测度及稳定研究

（18XTJ004）”资助。

\section{作者简介}

李强 (1969-) 男, 博士, 贵州财经大学金融 学院副教授; 覃春面 (1994-), 女, 贵州财 经大学金融学院硕士研究生。

\section{参考文献}

[1] Abdullah A. Crisis transmission: global financial crisis. Journal of Risk Analysis and Crisis Response, 2012, 2(3): 157-16.

[2] 徐明东, 陈学樹. 货币环境、资本充足 率与商业银行风险承担.金融研究, 2012, (7):48-62.

[3] 吴亚, 刘瑞环.我国商业银行规模与风险 承担关系分析. 商业时代, 2014, (33): 87-89.

[4] 刘志洋. 规模大的银行风险真的高吗?一 基于中国上市商业银行的实证分析.金 融论坛, 2015, (1):66-72.

[5] 谢俊明. 我国商业银行规模对银行风险 承担的影响研究.哈尔滨商业大学学报 (社会科学版), 2015, (6):71-78.

[6] 唐齐鸣, 马丽.利率市场化、银行规模及
其风险承担一基于我国上市商业银行 的实证研究. 武汉理工大学学报(社会科 学版), 2017, 11(6):16-22.

[7] 周再清, 甘易, 胡月. 商业银行同业资产 特性与风险承担行为一基于中国银行 业动态面板系统 GMM 的实证分析. 国 际金融研究, 2017, (7):66-75.

[8] 喻微锋, 周黛. 互联网金融、商业银行规 模与风险承担.云南财经大学学报, 2018, (1):59-69.

[9] 蔡允革.资本监管对我国商业银行资本 充足率和资产风险水平影响的实证研 究. 西部金融, 2008, (10):25-27.

[10] 江曙霞, 任婕茹. 资本充足率监管压力下 资本与风险的调整——基于美国商业 银行数据的实证分析. 厦门大学学报(哲 学社会科学版),2009,(4):79-85.

[11] 陈冠华, 杨晓奇.资本充足监管与商业银 行风险的实证分析.财经问题研究, 2010, 5(5):70-73.

[12] 魏晓琴, 张娜, 丛红媛. 我国商业银行资本 充足率与风险资产关系研究. 金融发展 研究, 2011, (12):63-64.

[13] 潘佐郑. 资本充足性与商业银行风险行 为.金融论坛, 2013, (11):29-35.

[14] 尹志超, 吴雨, 林富美.市场化进程与商 业银行风险一基于中国商业银行微观 数据的实证研究. 金融研究, 2014, (1):12 4-138.

[15] 牛丽娟. 资本充足率、股权结构与商业银 行风险承担的实证检验.统计与决策, 2015, (22):155-157.

[16] Shrieves R, Dahl D. Therelationship between risk and capital in commercial banks, Journal of Banking and Finance, 1992,16:439-457. 